\title{
$\mathrm{PH} 102$ reseñas
}

\section{Herráez, Juan A., Pastor, M.J. y Durán, D. (coord.) \\ Guía para la Elaboración e Implantación de Planes de Conservación Preventiva}

sl: Ministerio de Cultura y Deporte, 2019

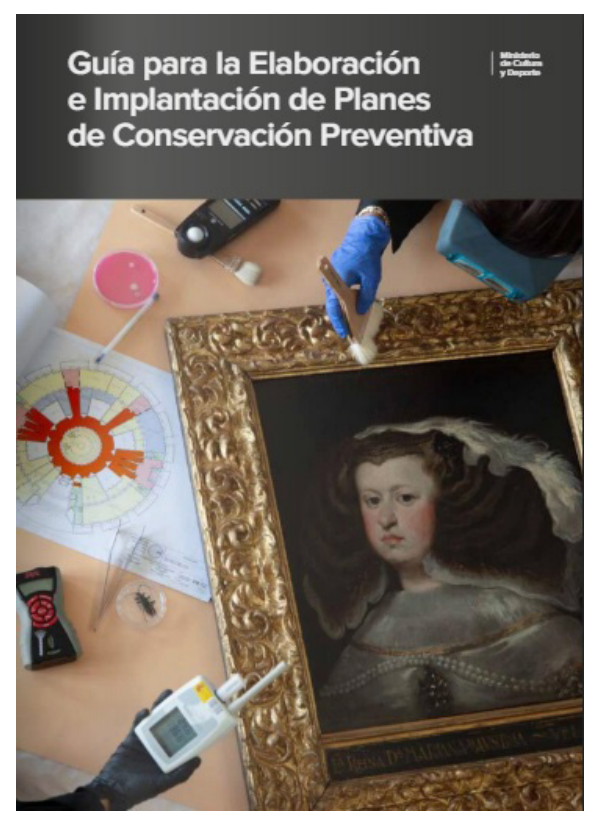

En la actualidad el mundo de la conservación y restauración se encuentra inmerso en grandes errores, a consecuencia de un mal planteamiento de las técnicas y por el desconocimiento de los procedimientos y teorías. Encontramos ejemplos insuficientemente ejecutados como, por ejemplo, el Ecce Homo de Borja o el rostro de la escultura de la pastorcilla de Palencia, entre otros. Con esta Guía para la Elaboración e Implantación de Planes de Conservación Preventiva escrita por varios autores y editada por la Subdirección General de Museos Estatales en 2019 se pretende difundir la conservación preventiva de los bienes, señalando el objetivo de la salvaguarda, para de ese modo evitar a posteriori desastrosas intervenciones de restauración y/o conservación.

Se facilitan herramientas para la elaboración del Planes de Conservación Preventiva (PCP) por parte de instituciones y técnicos cuya responsabilidad atiende a la conservación del patrimonio cultural. A su vez, se señalan los procedimientos y normas de control de calidad, como la gestión de salvaguarda de los bienes institucionales, etc. El plan de actuación propuesto consiste en elaborar un método de trabajo que ha de ejecutarse frente a los problemas que posean los bienes culturales. Gracias a la existencia del Departamento de Conservación Preventiva del IPCE (Instituto del Patrimonio Cultural de España) podremos controlar el método de trabajo del PCP, teniendo en cuenta que, para cada trabajo, el método empleado será flexible, atendiendo a las necesidades específicas correspondientes a cada bien cultural.

El libro se organiza en capítulos, numerados del uno al siete. En el primer capítulo se realiza un breve recorrido histórico por los hitos más importantes de la conservación preventiva, partiendo desde el momento en que surge como concepto en los años 90 del siglo XX. En el año 2000 en la reunión de Vantaa, y posterior resolución auspiciada por el ICCROM, se impulsa la nueva ley de conservación preventiva en Europa, fundamentada en las experiencias y problemas comunes a nivel continental. En el capítulo segundo, se expone que el Plan de Conservación Preventiva será una herramienta fundamental para seguir una misma metodología de trabajo siempre. Según el PCP, todo trabajo debe incluir varios aspectos fundamentales, los cuales señalarán el estado de conservación: documentación, análisis de riesgos, diseño e implantación de procedimientos y protocolos y verificación. 
El siguiente procedimiento lo encontramos desarrollado en el capítulo tres. En este apartado localizamos detallada la documentación que recoge información acerca del propio bien cultural, la institución y entorno al que pertenece, así como su gestión interna. En el capítulo cuatro se analizan los riesgos que pueden afectar a la estabilidad del bien cultural y se plantea el modo de actuación para erradicar el problema. Para facilitar la comprensión del contenido, se acompaña de ejemplos prácticos y gráficos para que el lector visualice lo que está leyendo.

En el capítulo quinto se explica el protocolo de seguimiento del bien para controlar su mantenimiento, deterioro o posibles actuaciones en caso de emergencia, teniendo en cuenta los recursos de cada institución. Esto debe reflejarse por escrito y detalladamente.

La última fase del PCP se plasma en el capítulo sexto, en el que se expone la verificación y supervisión continua de los procedimientos desarrollados para el control de calidad. Finalmente, en el capítulo séptimo se desglosan los nuevos aspectos y niveles de conservación, los cuales han sido detectados por el deterioro cíclico. Se realiza un nuevo Plan de Conservación Preventiva para mejorar el estado de conservación y la integridad del patrimonio cultural. En definitiva, es de vital importancia el proceso largo y costoso de salvaguarda del patrimonio. Por ello, es preciso recurrir a la concienciación y difusión del patrimonio, tal y como se puede desgranar a lo largo de las páginas de esta guía.

Nicolás Gallego Fernández | historiador del arte

URL de la contribución <www.iaph.es/revistaph/index.php/revistaph/article/view/4780> 